\title{
CDEN Design Module Development: A Developer's Perspective
}

\author{
Rashaad Sader \\ Faculty of Engineering \\ University of Calgary \\ rsaderl@ucalgary.ca
}

\author{
Daryl Caswell \\ Faculty of Engineering \\ University of Calgary \\ djcaswel@ucalgary.ca
}

\author{
Clifton Johnston \\ Faculty of Engineering \\ University of Calgary \\ johnston@enme.ucalgary.ca
}

\author{
Rod Fauvel \\ Faculty of Engineering \\ University of Calgary \\ fauvel@enme.ucalgary.ca
}

\begin{abstract}
In the formative stages of the Canadian Design Engineering Network, module developers are faced with a significant challenge. As developers, we want to create design modules representative of our own best practices, however, the modules we produce need to fit into an organizational structure that is still evolving. In the view of the authors, the fact that the structure is still evolving is a positive one. WE also view the establishment of one submission format prior to the creation of design modules is putting the cart before the horse in a project that relies on creative submissions from many different people with many different approaches to design education.. The purpose of this paper is to integrate a discussion of the current form of the Tier system with a description of the author's module development approach. Hopefully, as more modules are generated, a more flexible pattern for organization and integration will emerge.
\end{abstract}

\section{Introduction}

The goal of the Canadian Design Engineering Network is to facilitate the sharing of educational engineering design tools among all Engineering Schools within Canadian Universities. Through CDEN, the enormous effort required to run a successful design program can be supported by providing easy, web-based access to the wealth of projects, techniques and methodologies constantly being developed and refined by Canadian engineering design instructors. However, the realization of the ideal is proving to be a significant challenge. At issue is the fact that design and design education are fundamentally creative activities, and as such do not readily yield to standardization and formalization. The challenge, for both developers and administrators, is to create a web vehicle that is flexible enough to allow a range of approaches but organized enough to allow quick access to and integration between different approaches.

This paper is intended to examine the kinds of challenges facing a module developer. The experience of the authors is the result of many years of engagement with engineering design, engineering design education and program development. The authors have produced a design module as a part of a larger project on Product Development Process modules. The original PDP proposal planned for nine related modules. To date, the first three are in place (PDP Overview, Health and Safety, Concept Evaluation). Our module was on Concept Evaluation. 


\section{The Organization of Modules}

The fundamental framework for CDEN design modules is based on a three tier concept where Tier 1 modules are to address fundamental principles of engineering/science and engineering design -for example, the engineering concept of statics and the design concept of safety factors. Tier 2 modules are to address specific engineering techniques or processes - for example, the techniques of fastening and the process of design. Tier 3 modules are to provide a design activity that integrates the skills gained from Tier 1 and Tier 2 modules. The pattern of learning presumes to move from specific, teachable concepts to general, project-based study requiring integration of knowledge from Tier 1 and Tier 2 .

With this framework in mind, modules can be organized into larger units that address the broader issues of design like the Product Development Process. Ideally, the ever increasing capacity of the web will allow considerable facility and sophistication in the connections among a wide range of modules that exist within the Tier framework. Fundamentally, the Tier system is rooted in the assumption that correct design theory will yield correct design practice.

\section{The Challenge}

As a structure, the Tier concept seems to make sense. At first glance the step-like advancement from fundamentals to full projects is clear and logical. The logic is similar to that of non-design engineering courses: correct theory yields correct practice. Unfortunately, there are a number of disconnects between the intent of the Tier framework and the realities of teaching and doing design that make the job of module development a daunting task. In fact, in order to pull together a module on Concept Evaluation, the authors found it necessary to put the Tier system aside and develop the module in the light of successful practice and pedagogy. Since the Tier system is in its infancy the hope is that, given real modules, the framework will evolve to accommodate the needs of module developers and therefore encourage participation.

\section{The Issues}

If CDEN is to succeed, there must be a compatible framework for both developers and users of the design modules. However, the framework will necessarily have to be flexible. Otherwise, potential module developers are likely to avoid participation because they find the framework constraints too limiting. What follows is discussion of the current form of the organizational structure.

Presently, the Tier concept supports the view that design is a process that can be learned through the application of well defined procedures and skill sets. The match between the Tier concept and the traditional design process seems to be good. However, the use of the design process as an educational methodology has been largely unsuccessful [1]. Even though the process does indeed document the main components of successful design, the ability of engineering students to grasp the significance of the steps in the design process is generally poor. Even at the professional level, blind adherence to a set procedure for design too often results in the creation of inferior products [6].

Therefore, the CDEN Tier system must strive to support successful methodologies rather than set procedures. Still, from an organizational standpoint it would be convenient to adopt a single, traditional unifying methodology. However, the reality of engineering design education is that most successful programs are not from the traditional mold. In fact, successful approaches often borrow from a number of nonengineering disciplines. Fortunately, across disciplines, design problem spaces share many common features. Design problem spaces also differ in significant ways from nondesign problem spaces [5]. In the view of the authors, the Tier system, in its present state, is more geared to nondesign problem spaces, where correct theory leads to correct practice, than to design problem spaces where, according to Snodgrass [8] the assumption that correct design theory will yield correct design practice does not hold in the classroom.

The problem identified by Snodgrass arises from the assumptions of the rational paradigm which assume that, with proper training, people can be entirely rational and make decisions based on logical argument [9]. Accordingly, design problems can be reduced to a fundamental set of constraints that can be worked through in a logical fashion resulting in a design solution that satisfies those constraints. The Tier system accepts these assumptions of logical rationality and supports their development.

However, Fisher [9] proposes that the assumptions of the traditional rational paradigm 
limit our understanding of reason and rationality by separating logic from everyday discourse. Design spaces require a forum for discourse because successful design evolves from a synthesis of many points of view or ways of knowing about the world. Without discourse, this crucial synthesis cannot take place. Rittel [2] describes the act of design as the telling of a story. Therefore, to be successful, the Tier system must be able to support discourse and synthesis by accommodating a wide range of successful design stories.

This is the central conflict experienced by the authors as module designers who wish to develop modules that capitalize on the richness and intrinsic connectivity of design discourse rather than (typically post hoc) on design logic. Although most canned design activities can be deconstructed into a series of logically constructed steps, the end result of methodically following the sequence is that the sum of the parts is less than the whole: design logic is achieved but design discourse and synthesis are thwarted. In our view, breaking design activities into a series of tiered events that are assumed to be common to all design projects negates synthesis. In our view, synthesis is the most important skill of the designer and the difficulty in developing adequate design skills is due in part to the failure to continually develop both the skills of synthesis and the associated technical knowledge base into the engineering curriculum [4].

The Tier system, as it stands, focuses only on a relatively narrow slice of the technical knowledge base and does not support or include synthesis. Using architecture as an example, "most architectural educators think their task is to teach students how to design architecture according to conventionally formal mechanism" [10]. This kind of approach fails because of the dominance of rationality to the exclusion of the more humanistic activity of synthesis that characterizes successful design[11]. Synthesis is a skill rooted in humanism. The act of creative design is entirely human but not entirely rational, and according to Sternberg, other disciplines share the view that good design seeks to reintegrate the human experience [12]. Synthesis is the means for achieving that reintegration.

Therefore, the structure and ordering of CDEN design modules should seek to support both the skills of synthesis and the development of technical knowledge. Tier 1 and Tier 2 activities support specific technical skill development without consideration for development of synthesis skills. Tier 3 activities support integration but not synthesis. The point of this paper is to encourage a web-based organization and structure of CDEN design modules that supports synthesis. As module developers, we seek to develop modules that display our own success stories through our best practices in the combination of synthesis and technical knowledge.

\section{Module Development}

As mentioned previously, after spending a considerable amount of time wrestling with the desire to support and contribute to CDEN versus the need to tell our design story as a whole rather than as a Tier 1, 2 or 3 event, the authors decided to set aside the directives implied by the Tier system and develop the module according to best practices with the hope that the Tier system will evolve to accommodate best practices. What follows is an explanation of our approach to developing a module on concept evaluation.

To begin, the goal of CDEN is to facilitate the sharing of educational engineering design tools among all Engineering Schools within Canadian Universities. The design education tools developed by the authors have evolved from our view of the fundamental goal of design education: to prepare students to be innovative problem solvers.

Innovative problem solvers must be able to think independently. Independent thought is not supported by a formulaic, step-by-step methodology. Rather, independent thought and therefore innovation is fostered by allowing the students to draw on their own knowledge and experience [13]. The key elements for the success of the educational engineering design tools developed at the University of Calgary are the following:

1. Students are not empty vessels. Each student, whether $1^{\text {st }}$ year or $4^{\text {th }}$ year brings a wealth of knowledge into the classroom [13]. This knowledge forms the basis for developing the skills of synthesis [3].

2. Students must put forth their own ideas about the design problem and justify their thinking before receiving input from the instructor [7].

3. Students need to supplement the traditional engineering design process with a focus on design activities which we define as: Familiarization, Functionality and Testing [1]. 
4. Exposure to other disciplines and other ways of thinking is central to developing design skills in general and synthesis in particular [13].

5. Each design activity should immerse the student in design as an integrated whole (with its associated uncertainties) rather than as an isolated step or event. This we refer to as participatory inquiry [3], [14].

The objective of the CDEN module on Concept Evaluation was to provide a training tool that introduces engineering students (primarily first year) to the topic while engaging them in the activities of design and exposing them to professional standards.

Concept Evaluation is a design technique that contains the following:

1. A forum for the expression and justification of the ideas of the designer

2. A forum for the input of the user/subject experts

3. A framework for decision-making regarding the advancement of the design.

However, first year engineering students lack experience and familiarity with the range of engineering methods and topics that are prerequisite for the effective use of concept evaluation as a part of the traditional engineering design process.

In the opinion of the authors, most design texts try to compensate for this deficiency by presenting problems that are comprised of clear theoretically based textbook problems centred on formulaic manipulation. Such problems are referred to as "tame" problems [2] and are characterized by well traveled solution paths that always yield the same answers. Tame problems provide little value in highlighting the benefit of the traditional design process for solving real world or "wicked" problems.

Wicked problems are problems that have no existing satisfactory solution, no known solution path and often no idea of what the problem actually is [2]. Wicked problems characterize the day to day work of the professional engineer. The authors support the notion that, in design education, you must start as you wish to finish. In other words, if we want our students to be able to handle wicked problems, we must present them with wicked problems from the beginning. Saving the exposure to wicked problems until the end of their education requires a midstream change of mindset that is rarely successful.

Therefore, to appreciate the design process, novice engineering designers need to attack wicked problems. These wicked problems should encourage students to nurture their synthesis skills (i.e. their ability to bring together different points of view) rather than their analysis skills that are well served by the majority of engineering coursework. Even though first year students typically lack adequate engineering knowledge, wicked problems can still be explored by utilizing the knowledge students have already developed in order to function in their own world [3], [13].

For example, problems that require an understanding of consumer behaviour can readily form wicked problems manageable by first year students.

As young adults, students are already consumers, and as consumers they have an intuitive understanding of marketing strategy. In addition, there are many opportunities to employ the design activity trinity of familiarization, functionality and testing [1] through the readily available opportunities to collect data and make observations by exploring local stores.

As another example, decisions that require moral judgment resulting in a yes or no answer also form wicked problems. In any question of moral judgment there is no clear right or wrong answer. Regardless of the answer, the strength of the decision is in the quality of the justification. So it is with design.

The use of such seemingly non-engineering projects allow students to fully engage in the activities of design in general and in concept evaluation in particular without diluting the design experience in order to compensate for a lack of technical knowledge. They learn to synthesize knowledge they already possess and knowledge they can readily access.

As a result, the decision was made to address problems outside of engineering and to focus on problems that lie within the experience of students. We selected a marketing problem: the struggle of local merchants to compete with large chain stores. We also selected a legal/moral problem: the taking of one life in order to save many lives. These are problems that students have experience with and/or opinions about. The objective for both activities is to engage the students in the design-oriented struggles of developing and defending a solution or point of view. The culmination of the activities is the set up and execution of a Concept Evaluation event. 
In order to set up a successful concept evaluation, novice designers must engage fully with the activities of design that lead up to the event. They will need to familiarize themselves thoroughly with the situation to develop an understanding of the nature of the problem. They will need to determine what function the solution is supposed to achieve and they will have to develop tests that validate their decision pathways. With these activities underway, the Concept Evaluation event will function as a proving ground, an information gathering opportunity, and a decision point.

In order for the event to be effective, students will have to ask the right questions. Students who are novice designers and novice engineers have little hope of knowing what to ask when faced with a highly technical design problem. However, if the design problem draws from experiences they already have, the students are able to capitalize on their own knowledge and intuition.

\section{Concept Evaluation Challenges}

Certainly, the act of developing and defending a point of view regarding the solution to either the marketing or the ethical dilemma exposes the students to the activities of design leading up to a Concept Evaluation event. The central tool for Concept Evaluation is the planning and implementation of the design review.

Design reviews tend to be viewed very differently by instructors and by students. Instructors see the design review as an opportunity for student designers to truly engage in a collaborative decision making process.

Students, however, are conditioned to view any form of presentation as another form of assessment. In particular, students believe that weaknesses are to be downplayed and strengths emphasized in order to achieve the best mark possible. This is contrary to the purpose of a design review where weaknesses should be identified and addressed.

As well, students have little experience in critiquing the work of their peers and tend to shy away from actively engaging in debate. The challenge here is to create an environment where students are comfortable discussing their ideas, speaking freely about the work of their peers and assessing the qualities of a proposed design.

Therefore, the authors employ an improvisational presentation technique where students, with minimal notice, present the anonymous work of other students. Prior to the design review event, the students are provided with a comprehensive design review reference, developed at the University of Calgary [15] which describes the purpose, function and implementation of a professional engineering design review and the presentation and explanation of decision making tools (prioritization matrices and Kano models).

Central to our approach is the creation of a link between the first year concept evaluation project and real, professional engineering best practices. By making these links through our professional level design toolbox, students are able to develop the necessary skills for concept evaluation while being exposed to professional quality engineering concepts.

In order to assist with the running of the module, we included assignments, presentation material and the higher level reference material suitable for professional work.

\section{Module or Not?}

At the end of the project, the authors were pleased with the result on two levels. First, the module displayed the best practices that have worked well for our program. Secondly, we now have a new addition to our own design education toolbox.

However, we also have a number of concerns. First, is it a module at all in the context of the Tier system? It contains components of all three tiers and yet conforms to none of them. Second, in order to use the module effectively, does an instructor have to buy in to the entire approach or can it stand alone? Third, can or should the module be reconstructed to conform to a unifying format and can this be done without compromising its effectiveness? Fourth, had we attempted to keep the organizational framework in mind from the beginning, would we have carried it through to a result that we believe in? Fifth, is it possible to create an integrated webbased resource that can make meaningful links between the many different successful approaches to teaching design? And finally, is it true that every tool carries with tacit assumptions about the way in which it is to be used and, if so, how can CDEN support that important knowledge base? 


\section{Conclusion}

The goal of CDEN is to enable the sharing of design engineering education tools amongst instructors at Canadian universities. In the current developmental stage CDEN is seeking to balance the desire for a unifying organizational strategy with the need of module developers for flexibility. This paper has attempted to discuss the current form of the organizational structure as it stands in the light of our own philosophy of design education and to illustrate the thought processes behind the development of one module on Concept Evaluation. Overall, the view of the authors is that "Tiers are not enough".

\section{References}

[1] Caswell, D.J., Johnston, C.R., Fauvel, O.R., Douglas, D., Eggermont, M. "Fundamentals of a First-Year Engineering Design and Communication Course: Familiarization, Functionality and Testing", Proceeding of ASEE Conference, Salt Lake City, 2004

[2] Rittel, H.W.J., "Impressions of Architecture 130: Notes and Observations of Prof. Horst W.J. Rittel's Classic Design Methods Course at Berkeley as taught circa-1969-1971" Design Methods, Theories, Research, Education and Practice, 1996 Vol 29 no. 1 to vol. 32 no. 4

[3] Caswell, D, Johnston, C., Douglas, D., Eggermont. M. Fostering Creative Problem Solving in a Multi-Disciplinary Environment Monogram published by the

Society for Teaching and Learning in Higher Education, McGraw Hill, Columbus, $\mathrm{OH}$, in press.

[4] Fauvel, R., Winkelman, P., Organization of Technological Information for the Novice Mechanical Designer, International Workshop on Pedagogics in Design Education, International Society for Design Science of Engineering Design, Pilzen, Czech Republic, November, 1998.

[5] Goel, V., "A Comparison of Design and Nondesign Problem Spaces", Artifical Intelligence in Engineering, 9 (1), 1994, pp. 5372

[6] Mansour, Y. "Researching Design: Conceptual Framework" Design Methods: Theories, Research, Education and Practice, Vol. 33 No. 2, 1999 pp: 2825-2836

[7] Fisher, William, R. Human Communication as Narration: Towards a Philosophy of reason, value, and action. Columbia, SC: University of South Carolina Press, 1987

[8] Snodgrass, A. "On Theorizing Architectural Education" Architectural Theory Review: Journal of the Department of Architecture, University of Sydney Vol. 5 no. 2, Nov. 2000, pp. 89-93

[9] Fisher, William, R. "Narration, Reason, and Community." Memory, Identity, Community: The Idea of Narrative in the Human Sciences, Ed. Lewis P. Hinchman and Sandra K. Hinchman. Albany, NY: State University of New York Press, 1997. 307-327.

[10] Hui, Zou. "From Foucault's Concept of Discourse to Building as Comparison", Design Methods: Theories, Research, Education and Practice, Vol, 33 No. 4 (Dec. 1999), pp: 29092917

[11] Khisty, C.J., Leleur S. "Citizen Participation Through Communicative Action: Towards a New Framework and Synthesis", Journal of Advanced Transportation 31 (2), 1997, pp. 119-137.

[12] Sternberg, E. "An Integrative Theory of Urban Design", Journal of the American Planning Association 66(3): 265-278

[13] Schneider, B., Caswell,D. "Building Community and Creating Knowledge in the Interdisciplinary Classroom" History of Intellectual Culture, 3(1) http://www.ucalgary.ca/hic

[14] Reason, Peter. "Three approaches to participative inquiry." Handbook of Qualitative Research. Eds. Norman K. Denzin and Yvonna S. Lincoln. London: Sage, 1994. 324-339 [15] Brusse-Gendre, T., A Toolbox Approach to Design Education, M.Sc. Thesis, The University of Calgary, 2002. 